\begin{tabular}{|c|c|c|}
\hline $\begin{array}{l}\text { EXCELLENT } \\
\text { PUBLISHERS } \\
\end{array}$ & $\begin{array}{c}\text { International Journal of Current Research } \\
\text { and Academic Review } \\
\text { ISSN: 2347-3215 (Online),:Nolume 5;, Number } 6 \text { (June-2017) } \\
\text { Journal homepage: http://www.ijcrar.com }\end{array}$ & 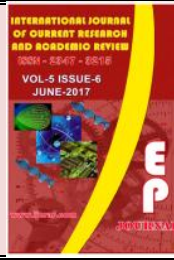 \\
\hline
\end{tabular}

doi: https://doi.org/10.20546/ijcrar.2017.506.008

\title{
Evolution and Classification of the Gymnosperms-A Review
}

\author{
Teena Agrawal* and Priyanka Danai
}

Banasthali University, Niwai, India

*Corresponding author

\begin{abstract}
Gymnosperm are the plants of the remarkable importance, they Have the long evolutionary history, form the evolution point of view these groups form the importance's in the plant kingdom, in this series these plant groups are adapted for the best xeric conditions, the evolution of the vascular system as well as other parts of the plants can be best seen in that group. The evolution of all the organs form roots to the shoots is also the another point of interest. We can observe the cladistics as well as the punctuated equilibrium in the gymnosperms. Mesozoic era was the time of the basic flourish of the gymnosperm in the geological time scale, due to rapid evolutionary changes of the nature and the geological revolutions these groups are very relicts. Well now a day only a belt of the distribution of the gymnosperms can be seen all over the world, some of the northern hemisphere are the point of the distribution of the gymnosperms, in India some mountainous places are the point of the distribution for the gymnosperms. Sustainable utilization and conservation of the gymnosperm is the essential features for the propagation of these plants groups.
\end{abstract}

\section{Article Info}

Accepted: 05 June 2017

Available Online: 20 June 2017

\section{Keywords}

Gymnosperm,

Cladistics,

Evolution,

Evolution of the organs,

Propagation.

\section{Introduction}

Plants are the best gift of the nature. They have been classified in various ways. Evolutioanry classification is the point of interest for the analysis of the plants from the centuries. From the time of the Aristotle the plants have been classified on the basis of the artificial charters. In this series they outlines the primary level of the classification like herbs shrubs trees, as the research proceeds than the parameters for the classifications was also changed from time to time. However, from Carolus Linnaeus to Bentham and Hooker, Engler and Prantl to Hutchinson have considered the evolution as the basic part of the research. Since at the time of the eminent peoples they have not the appropriate sources for the analysis of the plants but as the scientific research proceeds they utilized the evolution and analyze the evolution from the differ kind of the instrumentation and recent researches.

Gymnosperm are the plants which were always the points of interest, however a very limited places has been given to these plants in previous classification. From the beginning of that centaury many prominent gymnosperm scientist starts there studies on these vast group of the plants. In this series C.J. Chamberlain sir, T. M. Harris, Arnold and A.J. Eames are the prominent names for the gymnosperms.

These plants also have very long fossils history from the Pteridospermales to the fossils conferrals. Majority of the gymnosperms have extinct from the line of the evolution(Harris T.M.1928).the pteridospermales are the seed ferns that are typical intermediate from the ferns 
and the gymnosperms, it is a large assemblage of the many plants having the tree like ferns e.g. Sagenopteris, Sphenopteris, Cyclopteris and Pecopteris are the few representative of the order.

These are the intermediate between the ferns and the cycadophytes. These plants show the first step in the evolution for the bearing of the seeds on the leaves.

Pteridospermales have seven families

\% Lyginopteridaceae
\% Medullosaceae
\% Calamopyticeae
\% Caytoniaces
* Peltasermaceae
* Glossopterdacea
* Calamopitaceae

From the fossils analysis we can trace out the long fascinating history of these plants group, these plants have long evolution of all plants parts. A number of the views have been given for the evolution of these group (Stevenson and Delevoyros, 1956).

Bennettitales (Cycadiodaes) is another fascinating group that has attract the attention of the palaeobotansit from the 1825 after the finding of the Bucklandia from the sandstone cast of the great Britain. These plants have been observed in the form of the petrifaction and they flourish well in the Jurassic to the Triassic era of the geological time scale. They resemble very much to the cycads, so that the era has been termed as ages of the cycades. well the resemblance of the cycadales is superficial, there are many difference in the anatomy of the plants like these plants have syndetochelic stomata whereas cycadales have the haplochelic stomata (Thomas, 1923). There are many other anatomical differences which can be traced out in the bennettitales as well as the cycadales. The reproductive organs are the flower like organization, which is the evolutionary step in the evolution of the flowers of the angiosperms. There are some important features' of the bennettitales flower which shows that these plants have originated the angiosperms flower (Arber and Parkin, 1907).

These group of the plants have been found in the form of the petrifaction and the compressions'. Bennettitales have been classified in to the two families.

1. Williamsonia

2. Cycadoidea
Bennttitales plants have long and very important evolutionary significance, since in the evolution of the angiosperms the origin of the angiosperms has been trace out from the Bennettitales, the theory of the origin of the angiosperm also supports the origin of the angiosperm flowers.

Pentaxylales is the order which has been proposed by the professor Birbal Sahani in 1948. From the group of the plants that has been observes from the Rajamaham hills of the India. The group includes a number of the plants parts like the a number of the stems (Pentoxylon, Nipaniloxylon, Nipaniophyllum, Pollen bearing organ Shania, ovules bearing organ Carnaconites. prof birbal sahani and the shrivastava have done a number of the research work on this group of plants. These groups of the plant have a combination of the features of the bennttitales, cycadales and the conferlaes.

\section{Classification of Gymnosperm}

IT was Robert brown (1827) who first recognized Gymnosperm as a separate group of plant. Bentham and Hooker (1883) while classifying Angiosperm placed them in between dicotyledons and monocotyledons in their book Genera Plantarum.

Sporne (1965) classified Gymnosperms into 3 Classes.

\section{Class-1: Cycadopsida}

4 orders: Pteridospermales, Bennettitales, Pentoxylales and Cycadales.

Class: Cycadopsida is characterized with plants are palm like, leaves pinnate with central midrib; megasporophylls are not aggregated in cones, but borne separately like foliage leaves; Megasporophyll bears two or more ovules. Microsporophylls aggregate to form male cone. Eg. Cycas

\section{Class-2: Coniferopsida}

4 orders: Cordaitales, Coniferales, Taxalesand, Ginkgoales.

This class is characterized with mostly ever green trees, leaves are needle or scale like, wood contains resin canals, male and female cones are present e.g. Pinus

\section{Class-3: Gnetopsida}

1 order: Gnetales; 
This class is characterized with trees, shrubs or woody climbers, vegetative appearance is mostly like angiosperm with large leaves, oval and entire wood contain vessels. Male strobilus contains staminate flower and female strobilus contain ovules e.g. Gnetum (Fig. 2).

Bentham and Hooker (1862-1883): placed them between Dicotyledons and Monocotyledons as under (Fig. 3):

Van Tieghem (1898): who, on the basis of some earlier embryological and developmental studies, removed Gymnosperms from this intermediate position and considered them as follows (Fig. 4),
Proposed by A. Cronquist, A. Takhtajan and W. Zimmermann (1966) (Fig. 5):

In this classification the embryo-bearing plants (Embryobionta) have been divided into eight divisions, viz., Rhyniophyta, Bryophyta, Psilotophyta, Lycopodiophvta, Equisetophyta, Polypodiophvta, Pinophyta and Magnoliophyta.

All gymnosperms are included under Pinophyta, which is further divided as under:

Fig.1 Evolution of the gymnosperms

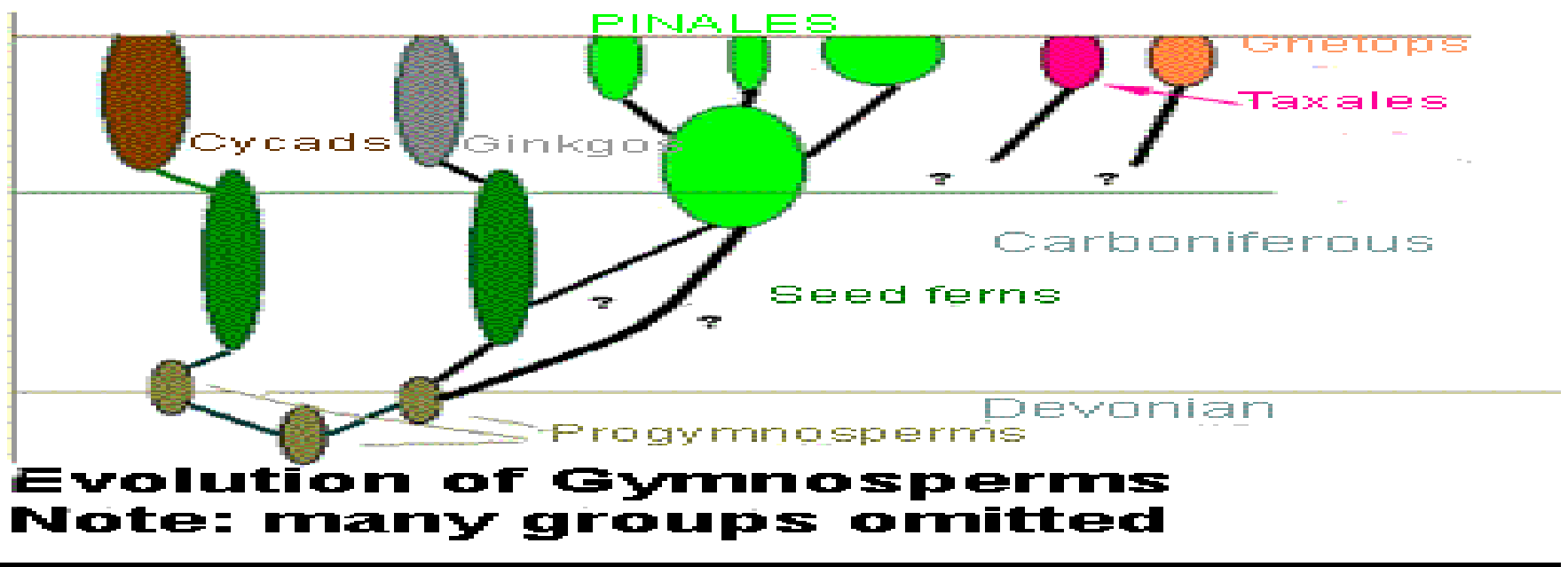

Fig.2 Cladistics of the gymnosperms

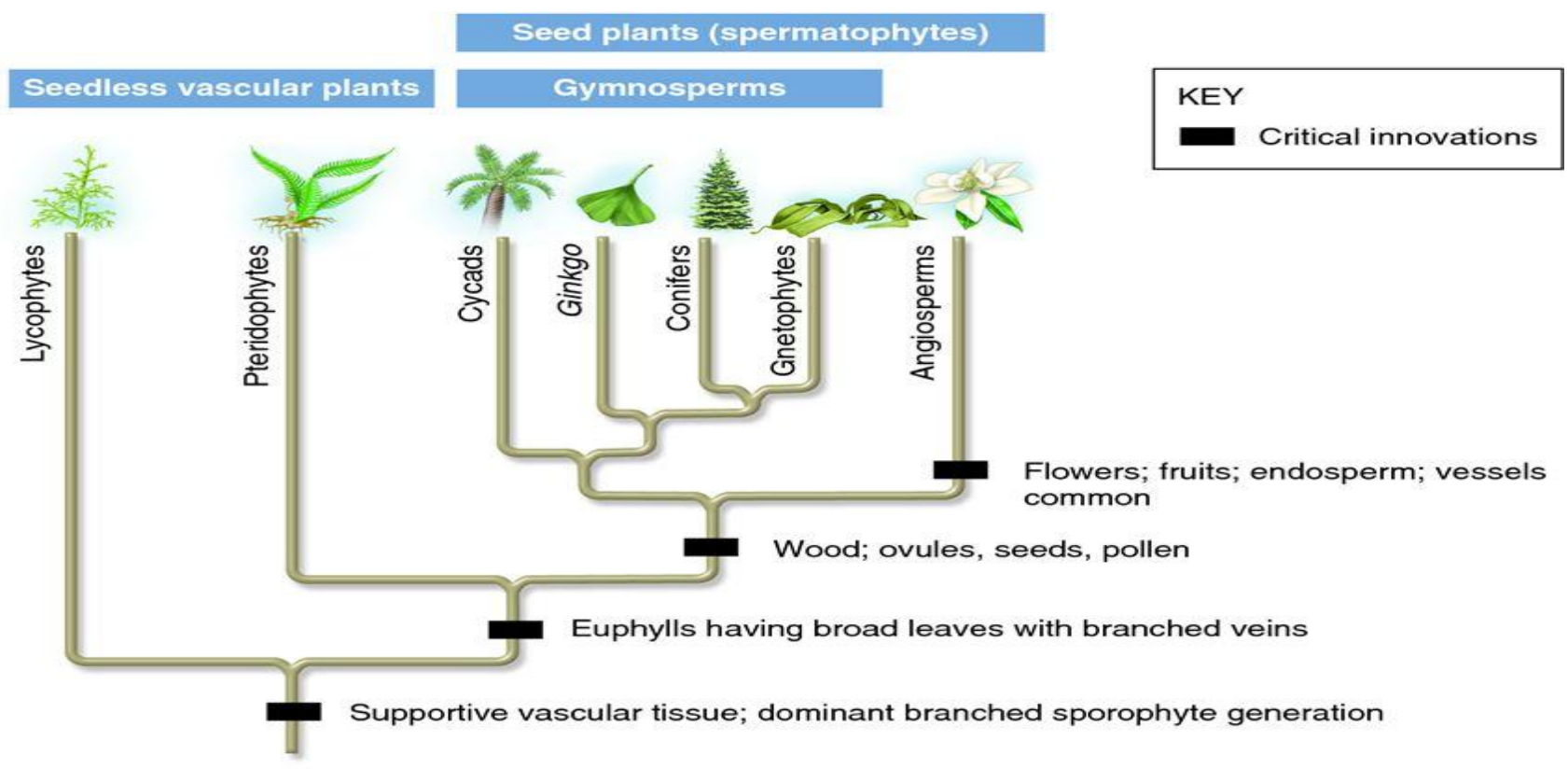


Fig.3 Bentham and Hooker classification

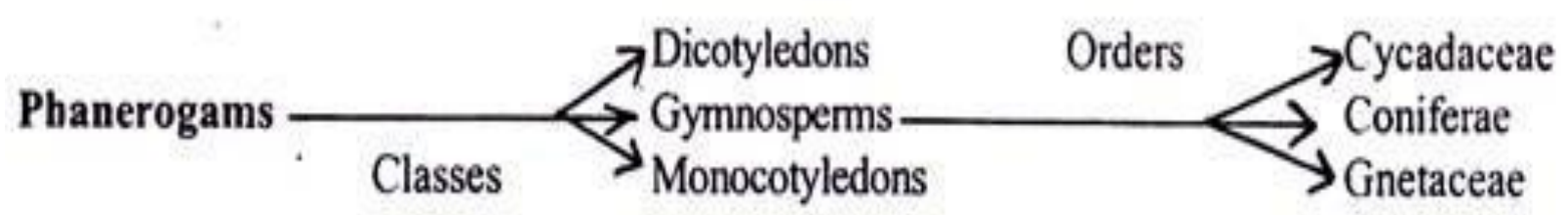

Fig.4 Van Tieghem classification

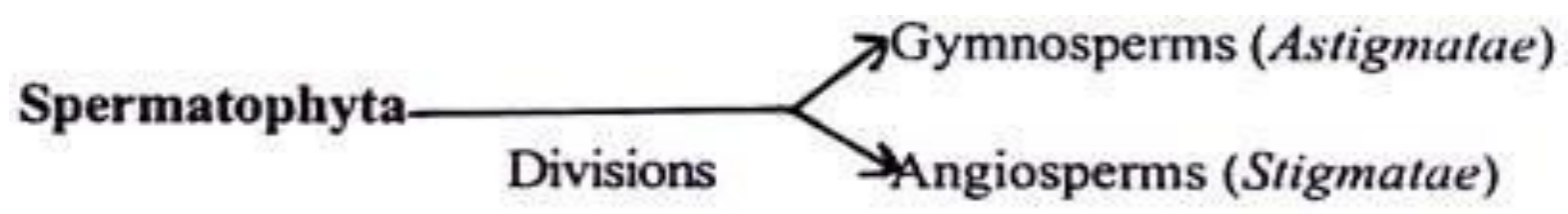

Fig.5 A. Cronquist, A. Takhtajan \& W. Zimmermann classification

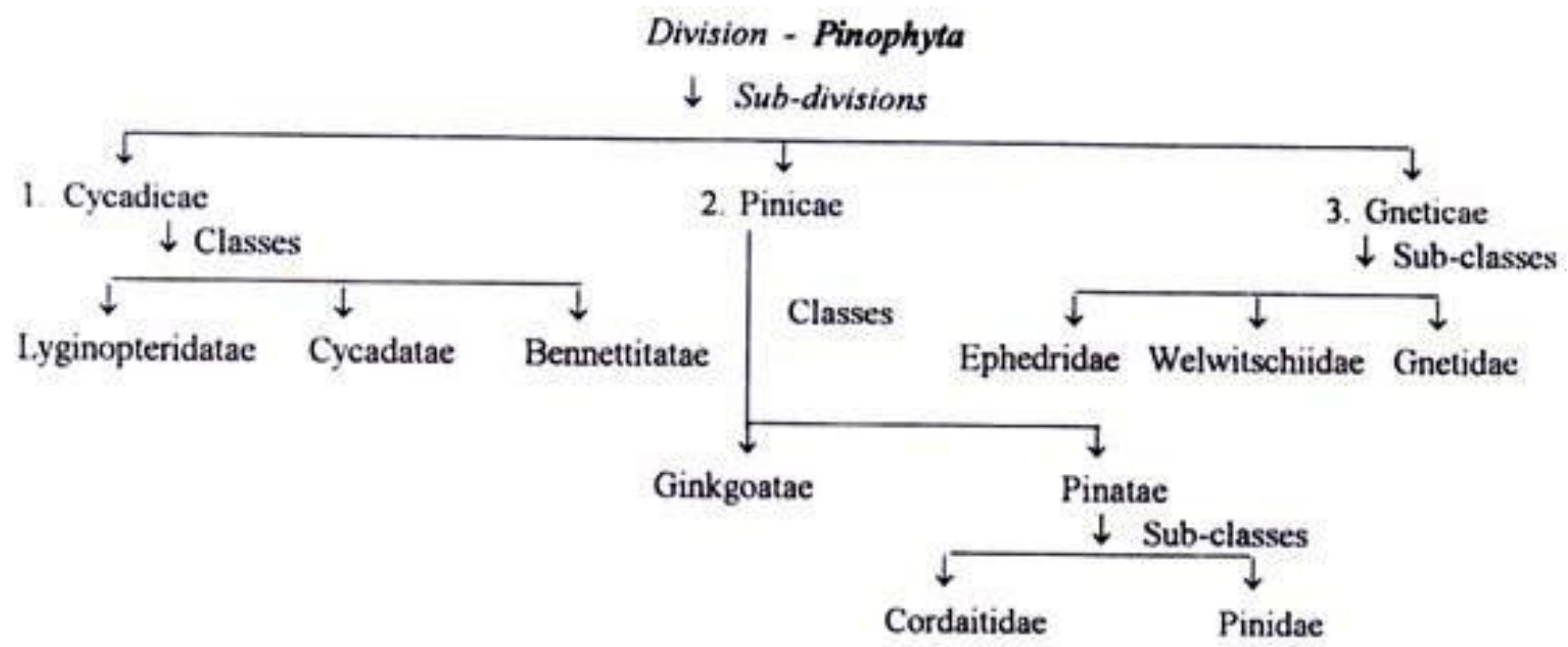

Coulter and Chamberlain (1917) divided the gymnosperm directly into two divisions: seven order

1. Cycadofilicales;

2. Bennettitales;

3. Cycadales;

4. Cordaitales;

5. Ginkogoales;

6. Coniferales

7. Gnetales.

A. Class Cycadophyta: It is characterized by unbranched and stumpy stem; leaves large and pinnately divided; male cone large and compact with simple sporophyall; female cone loose and consist of pinnate or simple porphyries that bear large ovel; stem have wide cortex and manoxylic wood. It include three order
- Cycadofilicales:

- Cycadeoidales:

- Cycadales:

B. Class Coniferophyta: The stems are profusely branched and the foliage give cone-like appearance; leaves simple; male and female strobili are compact and bear complex sporophyall; wood is pycnoxylic. It includes 4 orders:-

- Cordaitales: Extinct order.

- Ginkgoales: Includes extinct and one living representative.

- Coniferales: Includes both extinct and living genera.

- Gnetales: Includes both extinct and living genera. 


\section{Conclusion}

Gymnosperms are the plants have the exposed ovules, without the fruit, they are intermediate in evolution from the pteridophyte and the angiosperms. Economically these plants group are very important, since all plants part are the reservoirs' of them any kinds of the metabolites of high medicinally values, however due to rapid degradation of the forest and the ecosystem these group are degrading form the tremendous speed, now a day a few belt of the pants can be seen in some part of the world as well as in India.

The Indian peoples and the peoples of the other part of the world are unaware from the importance of this remarkable group of the plants.

So with the public awareness and the recent biotechnological experiments these group of the plants need conservation.

\section{References}

Ananiev, A. R., in Osnovy Paleontol., 15, 315-343 (1963).

Andrews, H. N., Studies in Paleobotany (Wiley, New York, 1961).

Arber, E. A. N., Ann. Bot., 28, 81-108 (1914).

Arber, E. A. N., and Goode, R. H., Proc. Camb. Phil. Soc., 18, 89-104 (1915).

\section{How to cite this article:}

Teena Agrawal and Priyanka Danai. 2017. Evolution and Classification of the Gymnosperms. Int.J.Curr.Res.Aca.Rev. 5(6), 56-60. doi: https://doi.org/10.20546/ijcrar.2017.506.008
Arnold, C. A., Bot. Rev., 4, 205-234 (1938).

Chaloner, W. G., J. Linn Soc. (Bot.), 61, (384) 25-36 (1968).

Forbes, E., Br. Ass. Rep., London, 43 (1853).

Gayer, R. A., Allen, K. C., Bassett, M. G., and Edwards, D., Geol. J., 8, (2) 345-374 (1973).

Johnson, T., Scient. Proc. R. Dubl. Soc., 15, 245-254 (1917).

Long, A. G., Trans. R. Soc. Edinb., 66, (14), 345-374 (1966).

Long, A. G., Trans. R. Soc. Edinb., 64, (12) 261-280 (1960).

Long, A. G., Trans. R. Soc. Edinb., 64. (15), 401-419 (1961).

Matten, L. C., Lacey, W. S., and Edwards, D., Phytolologia, 32, (4) 299-303 (1975).

Pettitt, J. M., and Beck, C. B., Contr. Mus. Paleont. Univ. Mich., 22, (10), 139-154 (1968).

Pettitt, J. M., Biol. Rev., 45, 401-415 (1970).

Pettitt, J. M., and Lacey, W. S., Rev. Palaeobot. Palynol., 14, 159-169 (1972).

Rothwell, G. W., Am. J. Bot., 58, (8) 706-715 (1971)

Schopf, J. M., Rev. Palaeobot. Palynol., 20, 27-53 (1975).

Smith, D. L., Biol. Rev., 39, 137-159 (1964).

Stockmans, F., Mem. Mus. r. Hist. nat. Belg. 110, 1-85 (1948).

Stockmans, F., Mem. Mus. r. Hist. nat. Belg., 159, 3-49 (1968). 